\title{
Lipid composition of the digestive glands of Mytilus edulis and Carcinus maenas in response to pollutant gradients
}

\author{
J. M. Capuzzo, D. F. Leavitt \\ Department of Biology, Woods Hole Oceanographic Institution, Woods Hole, Massachusetts 02543, USA
}

\begin{abstract}
In field studies for the GEEP Workshop in Langesundfjord, Norway, changes in lipid content and lipid: protein ratios of digestive glands of Mytilus edulis and Carcinus maenas were reflected along the pollution gradient, with populations of $M$. edulis showing elevations in both parameters at the 3 most contaminated Sites $(2,3$ and 4$)$ in comparison to the reference site (1), and populations of $C$. maenas showing elevations only at Site 3 . In mesocosm experiments only $M$. edulis from the high dose basin showed elevations in lipid content and lipid ; protein ratios; C. maenas in the medium dose basin showed a decrease in both parameters. Analysis of lipid class composition for field and mesocosm samples of $M$. edulis reveal differences in response to contaminant gradients that reflect alterations in mobilization of triacylglycerols to phospholipid pools, reductions in phospholipid content, and nutritional condition. Changes in lipid class distributions of $M$. edulis from both field and mesocosm experiments correlate well with body burden data for tissue concentrations of aromatic hydrocarbons and/or polychlorinated biphenyls. Lipid class distributions of field samples of $C$. maenas indicate alterations in the mobilization of triacylglycerols, sterol turnover, and reductions in phospholipid content. The responses, which suggest that crabs from Site 3 are the most impacted, are not consistent with contaminant data from the field sites. Crabs from mesocosm experiments show no evidence of alterations in lipid class distribution in spite of a consistent trend in aromatic hydrocarbon tissue concentrations along the gradient. Differential responses of field and mesocosm populations of $M$. edulis and $C$. maenas are possibly the result of metabolic capacity for detoxification and differences in trophic transfer.
\end{abstract}

\section{INTRODUCTION}

Lipids are important in all living systems as energy reserves and as structural components of membranes and cellular organelles. Optimization of lipid storage and mobilization of lipid reserves are critical to the reproductive and developmental success of marine animals; an understanding of lipid metabolism in marine animals therefore provides insight to some of the biochemical and physiological processes regulating adaptive responses and reproductive success.

Lipophilic organic contaminants, such as petroleum hydrocarbons, polychlorinated biphenyls (PCBs) and other synthetic organic compounds, may become sequestered in lipid rich tissues of marine animals. Impairment of lipid metabolism with exposure to lipophilic contaminants has been noted by several investigators. Capuzzo et al. (1984) observed reductions in triacylglycerol synthesis and decreased mobilization of essential fatty acids to phospholipid pools among larval stages of the American lobster Homarus americanus with exposure to petroleum hydrocarbons. Caldwell et al. (1979) hypothesized that exposure of fish to PCBs resulted in changes in fatty acid profiles as a result of interactions between mixed function oxygenase and fatty acid desaturase systems. They observed a higher degree of fatty acid saturation in phospholipids of sculpin Leptocottus armatus exposed to Aroclor 1254 , a response that could functionally alter thermal adaptation. Other studies have shown that exposure to lipophilic contaminants may result in symptoms of essential fatty acid deficiencies (Darsie et al. 1976), changes in both phospholipid and triglyceride synthesis (Dzogbefia et al. 1978), changes in membrane fluidity (Reich et al. 1981), and suppression of triglyceride transport (Kato et al. 1982).

Responses of invertebrates, including bivalve molluscs and decapod crustaceans, to lipophilic contaminants may also result in changes in both neutral lipid and phospholipid pools, altering both adaptive and 
energetic responses. The changes in lipid storage of digestive glands of Mytilus edulis and Carcinus maenas in response to lipophilic contaminants were evaluated along a pollution gradient in Langesundfjord, Norway and in controlled mesocosm basins at the Solbergstrand Marine Research Station on the Oslofjord, Norway.

\section{MATERIAL AND METHODS}

Mussels Mytilus edulis and crabs Carcinus maenas were taken from the field and mesocosm collections delivered to the laboratory at the University of Oslo each day and coded for sampling day (see Bakke et al. 1988, Follum \& Moe 1988, for details of collections and design of mesocosm experiments). Animals of uniform size (mussels: 5.5 to $6.0 \mathrm{~cm}$ shell length, crabs: 3.5 to 4.0 $\mathrm{cm}$ carapace width) were selected, dissected, and the reproductive condition of $M$. edulis and the molt condition of $C$. maenas were noted. Only crabs in intermolt to early premolt (stage $C$ to $D_{0}$ ) condition and mussels similar in their reproductive condition were used for analyses. For mussels collected along the pollution gradient in Langesundfjord, reproductive activity was low and fairly uniform among different populations. In mesocosm experiments there was some variation in reproductive condition of mussels especially those in the high dose basin which had to be replenished during the experiment (Lowe 1988). Crabs collected from Langesundfjord were in various stages of molt condition and it was evident that molting activity was high for these populations. In the mesocosm experiments, crabs from each of the experimental basins showed no indication of molting activity, possibly because of the lower temperature in the mesocosm basins in comparison with the field (9 versus $17^{\circ} \mathrm{C}$ ).

Digestive glands were removed from each animal and 3 replicate samples of approximately $10 \mathrm{mg}$ each were dissected from each digestive gland and placed in microcentrifuge tubes, capped and stored at $-20^{\circ} \mathrm{C}$ until analysed. One sample was used for protein analysis, one sample for gravimetric lipid analysis and lipid class analyses, and the 3rd sample was archived for future reference.

Lipids were extracted from digestive glands using a triple extraction in chloroform: methanol as described by Sasaki \& Capuzzo (1984). After extraction, a $50 \mu \mathrm{l}$ aliquot was removed and analysed for total lipids by gravimetric analysis using a Cahn Model 29 electrobalance. The remainder of the extract was placed in a microcentrifuge tube, flushed with nitrogen, capped and stored at $-20^{\circ} \mathrm{C}$ until analysed for lipid class composition. Lipid classes were separated on matched SII chromarods according to the methods described by
Sasaki \& Capuzzo (1984) and quantified using an latroscan TH-10, Mark 3, set at a scanning speed of $0.42 \mathrm{~cm} \mathrm{~s}^{-1}$, hydrogen pressure of $8 \mathrm{~kg} \mathrm{~cm}^{-3}$ and airflow of $2000 \mathrm{ml} \mathrm{min}-1$. Polar lipids were separated using the chloroform-methanol-water $(80: 35: 3)$ system of Innis \& Clandinin (1981); the neutral lipids were separated by an adapted version of the solvent system developed by Christie \& Hunter (1979), consisting of dichloroethane-chloroform-glacial acetic acid-isopropanol $(92: 8.0: 0.1: 0.03)$ as described by Sasaki \& Capuzzo (1984). Together these solvent systems differentiate the following lipid classes: triacylglycerols, 1,2diacyiglycerols, monoacylglycerols, free fatty acids, sterols, steryl esters, phosphatidyl choline, phosphatidyl ethanolamine and sphingomyelin. Standard curves were generated for each lipid class and an internal standard was added to each sample before analysis. Both neutral and polar lipids were analysed for each sample. Each sample was analysed in triplicate and 3 replicate samples were analysed for each species and treatment.

For protein analyses, digestive glands were dried to constant weight at $85^{\circ} \mathrm{C}$. Protein was determined by biuret analysis using the methods described by Raymont et al. (1964). Lipid:protein ratios and lipid class ratios were calculated. Statistical differences among all parameters were determined by 1 -way analysis of variance, with paired comparison of means to relevant reference samples (Field site 1 and mesocosm control basin), using SAS and NCSS statistical packages (Sokal \& Rohlf 1981). Because of the likely variance to mean relation in lipid data, protein data and lipid:protein ratios, data were transformed by the formula $\ln (1+x)$ for statistical analysis.

\section{RESULTS}

For field populations of Mytilus edulis, elevations in lipid content were evident along the pollution gradient in Langesundfjord with mussels showing significant increases at Sites 2, 3 and 4 by comparison with the reference site (Table 1); 1-way analysis of variance of log-transformed data resulted in an F-ratio of 5.2 (on 3 , $20 \mathrm{df}_{;} p<0.01$ ). There was no significant difference in protein content among any of the populations and the lipid protein ratio therefore followed the lipid pattern of elevated levels at Sites 2, 3 and 4. However, only Site 3 values showed a statistically significant difference from Site 1 (and the overall analysis of variance failed to detect a difference).

Lipid class analysis of Mytilus edulis samples along the Langesundfjord pollution gradient (Table 2) demonstrated significant increases in triacylglycerol content $\left(F=116.1\right.$ on $\left.3.8 \mathrm{df}_{;} p<0.01\right)$ as well as other 
Table 1. Mytilus edulis. Lipid and protein content (mg per 100 mg dry wt) of digestive glands of mussels from Field sites 1 to 4 and 4 experimental mesocosm basins (C: control, L: low, $\mathrm{M}$ : medium, $\mathrm{H}$ : high-dose of a diesel oil and copper mixture). Means $\pm \mathrm{SE}, n=6$

\begin{tabular}{|cccc}
\hline Source & Lipid & Protein & Lipid: protein \\
\hline Site & & & \\
1 & $13.9 \pm 1.3$ & $46.5 \pm 1.9$ & $0.30 \pm 0.03$ \\
2 & $22.5^{\circ}+1.3^{\circ}$ & $48.7 \pm 3.1$ & $0.42 \pm 0.03$ \\
3 & $21.6 \pm 1.9^{\circ}$ & $51.3 \pm 1.3$ & $0.47 \pm 0.03^{*}$ \\
4 & $19.2 \pm 2.4^{\circ}$ & $50.6 \pm 2.7$ & $0.39 \pm 0.07$ \\
Basin & & & \\
C & $18.7 \pm 1.5$ & $48.0 \pm 2.5$ & $0.40 \pm 0.05$ \\
L & $13.6 \pm 0.9^{\circ}$ & $47.0 \pm 2.1$ & $0.29 \pm 0.01$ \\
M & $15.6 \pm 2.0$ & $52.0 \pm 2.7$ & $0.30 \pm 0.03$ \\
H & $28.1 \pm 1.4^{\cdots}$ & $55.7 \pm 4.4$ & $0.53 \pm 0.07^{*}$
\end{tabular}

For field sites, significant differences from reference site (1), for mesocosm basins, from control basin (C), indicated by ${ }^{\circ} p<0.05 ;{ }^{\cdots} p<0.01$

changes in neutral lipid pools (specifically, free fatty acids and diacylglycerols). A reduction in phospholipid content was evident only in mussels from Site 4 $(p<0.01)$, resulting in a significant difference in the ratio of neutral lipids to polar lipids among this population. Each population along the gradient demonstrated a highly significant increase over the reference site in the triacylglycerol:phospholipid ratio $(F=12.1$ on 3 , $8 \mathrm{df} ; p<0.01$ ).

In mesocosm samples of Mytilus edulis, significant differences in both lipid content and lipid : protein ratios were evident among the various experimental basins (lipid content: $F=12.3$, lipid : protein ratio: $F=6.6$, both on $3,8 \mathrm{df}_{i} p<0.01$ ), although the trends were not consistent (Table 1). As with field populations, high variation in these parameters were evident and may reflect both differences in reproductive condition (Lowe 1988) and nutritional state (Widdows \& Johnson 1988). Samples from the low dose mesocosm basin demonstrated a significant decrease in lipid content $(p<0.05)$, whereas mussels from the high dose basin had significantly elevated levels of both lipid and lipid:protein ratios. No significant difference in protein content was evident among any of the mesocosm samples.

Lipid class analyses of Mytilus edulis from the mesocosm basins revealed several significant differences among mussels from the low (L), medium (M) and high (H) dose basins in comparison with control (C) mussels but the responses were not consistent along the gradient (Table 2). For mussels from the $\mathrm{L}$ and $\mathrm{M}$ basins, significant decreases in total neutral lipid content $(p<0.01)$, elevations in phospholipid content $(p<0.01)$, and decreases in both neutral lipid:polar lipid and triacylglycerol : phospholipid ratios $(p<0.01)$ were evident. For mussels from the $\mathrm{H}$ basin, a significant increase in the total neutral lipid pool $(p<0.05)$ was observed, especially evident in the increase in monoacylglycerols; a significant decrease in phospholipid content was also observed, resulting in highly significant increases in both the neutral lipid:polar lipid and triacylglycerol: phospholipid ratios $(p<0.01)$.

For field populations of Carcinus maenas, significant elevations in total lipid content and lipid: protein ratios, by comparison with Site 1, were only evident at Site 3 (Table 3). One-way analysis of variance of log-transformed data resulted in an $F$ ratio of 15.8 for lipid content and 15.2 for lipid: protein ratios (both on $3,8 \mathrm{df}_{i}$ $p<0.01$ ). No significant difference in protein content was evident among any of the populations.

Lipid class analyses of Carcinus maenas populations (Table 4) indicate significant increases in triacylglycerol content at Sites 3 and 4 and in total neutral lipid content at Sites 2, 3 and 4 (the $F$ ratio for the latter

Table 2. Mytilus edulis. Lipid class composition (\%) of digestive glands. Means $\pm \mathrm{SE}, n=3$

\begin{tabular}{|c|c|c|c|c|c|c|c|c|}
\hline \multirow[t]{2}{*}{ Lipid class } & \multicolumn{4}{|c|}{ Field site } & \multicolumn{4}{|c|}{ Mesocosm basin } \\
\hline & 1 & 2 & 3 & 4 & $\mathrm{C}$ & $\mathrm{L}$ & M & $\mathrm{H}$ \\
\hline Triacylgycerol & $44.7 \pm 1.3$ & $59.1 \pm 0.3^{\cdots}$ & $59.1 \pm 0.1 \cdots$ & $60.3 \pm 0.1 \cdots$ & $67.0 \pm 0.3$ & $66.0 \pm 0.3$ & $57.5 \pm 0.5 \cdots$ & $63.0 \pm 1.5^{\circ}$ \\
\hline Diacylglycerol & $1.0 \pm 0.1$ & $0.1 \pm 0.0^{\cdots}$ & $0.5 \pm 0.1 \cdots$ & $2.0 \pm 0.1 \cdots$ & $0.1 \pm 0.0^{\cdots}$ & $1.1 \pm 0.1 \cdots$ & $0.7 \pm 0.1 \cdots$ & $0.5 \pm 0.1 \cdots$ \\
\hline Monoacylglycerol & $13.9 \pm 0.9$ & $14.3 \pm 2.2$ & $14.5 \pm 0.3$ & $15.9 \pm 0.2$ & $9.8 \pm 0.3$ & $9.9 \pm 0.5$ & $10.9 \pm 0.3^{\circ}$ & $18.6 \pm 0.2 \cdots$ \\
\hline Free fatty acids & $26.3 \pm 0.8$ & $12.6 \pm 0.2 \cdots$ & $14.2 \pm 0.4^{\cdots}$ & $12.6 \pm 0.3 \cdots$ & $15.5 \pm 0.2$ & $10.9 \pm 0.3 \cdots$ & $16.2 \pm 0.3$ & $12.5 \pm 0.8^{\circ}$ \\
\hline Phospholipids & $12.7 \pm 0.5$ & $11.7 \pm 1.0$ & $11.6 \pm 0.7$ & $9.2 \pm 0.7^{\cdots}$ & $7.0 \pm 0.6$ & $11.2 \pm 0.6^{\cdots}$ & $13.3 \pm 0.9 \cdots$ & $3.1 \pm 0.3^{\cdots}$ \\
\hline Other polar lipids & $0.0 \pm 0.0$ & $0.4 \pm 0.1$ & $0.0 \pm 0.0$ & $0.0 \pm 0.0$ & $0.6 \pm 0.1$ & $0.9 \pm 0.1$ & $1.3 \pm 0.1 \cdots$ & $2.2 \pm 0.1 \cdots$ \\
\hline Total neutral lipids & $86.0 \pm 1.2$ & $86.1 \pm 2.1$ & $88.3 \pm 0.7$ & $90.8 \pm 0.7^{\circ}$ & $92.4 \pm 0.5$ & $87.9 \pm 0.7^{\cdots}$ & $85.4 \pm 0.9 \cdots$ & $94.7 \pm 0.2^{\circ}$ \\
\hline Total polar lipids & $12.7 \pm 0.5$ & $12.1 \pm 1.0$ & $11.6 \pm 1.0$ & $9.2 \pm 0.7 \cdots$ & $7.6 \pm 0.5$ & $12.1 \pm 0.7^{\cdots}$ & $14.6 \pm 0.9^{\cdots}$ & $5.3 \pm 0.2^{\circ}$ \\
\hline NL: PL ratio & $6.8 \pm 0.2$ & $7.2 \pm 0.7$ & $7.6 \pm 0.5$ & $10.0 \pm 0.8^{\cdots}$ & $12.3 \pm 0.9$ & $7.3 \pm 0.5^{\cdots}$ & $5.9 \pm 0.4 \cdots$ & $18.0 \pm 0.8 \cdots$ \\
\hline $\begin{array}{l}\text { Triacylglycerol: } \\
\text { phospholipid ratio }\end{array}$ & $3.5 \pm 0.2$ & $5.1 \pm 0.4^{*}$ & $5.1 \pm 0.3^{\circ}$ & $6.6 \pm 0.5 \cdots$ & $9.7 \pm 0.8$ & $5.9 \pm 0.3 \cdots$ & $4.4 \pm 0.3 \cdots$ & $20.7 \pm 2.1 \cdots$ \\
\hline
\end{tabular}


Table 3. Carcinus maenas. Lipid and protein content of digestive glands. Means $\pm S E, n=3$ for field sites and $n=9$ for mesocosm basins

\begin{tabular}{|cccl|}
\hline Source & Lipid & Protein & Lipid protein \\
\hline Site & & & \\
1 & $6.1 \pm 0.6$ & $57.8 \pm 1.8$ & $0.11 \pm 0.01$ \\
2 & $7.0 \pm 0.9$ & $54.4 \pm 5.9$ & $0.13 \pm 0.01$ \\
3 & $18.5 \pm 3.9 \cdots$ & $51.1 \pm 2.1$ & $0.36 \pm 0.07 \cdots$ \\
4 & $5.4 \pm 0.4$ & $53.8 \pm 5.7$ & $0.10 \pm 0.01$ \\
Basin & & & \\
C & $28.4 \pm 4.2$ & $59.8 \pm 2.6$ & $0.39 \pm 0.05$ \\
L & $17.4 \pm 2.1$ & $59.1 \pm 4.6$ & $0.31 \pm 0.04$ \\
M & $12.6 \pm 1.4 \cdots$ & $64.0 \pm 3.7$ & $0.20 \pm 0.02 \cdots$ \\
H & $20.9 \pm 2.7$ & $59.5 \pm 2.3$ & $0.35 \pm 0.05$ \\
Statistical significance as for Table 1 & \\
\hline
\end{tabular}

being 13.0 on $3.8 \mathrm{df} ; p<0.01$ ). Reductions in phospholipid content were observed among populations from Sites 2,3 and $4(F=76.4, p<0.01)$; this resulted in highly significant increases in both neutral lipid: polar lipid ratios and triacylglycerol:phospholipid ratios at all 3 impacted sites, although crabs from Site 3 appear to be the most impacted. A marked reduction in sterol content was also evident among crabs from Site 3 $(p<0.01)$.

In the mesocosm experiment, only crabs from the medium dose basin demonstrated a significant reduction in both lipid content and lipid:protein ratios $(p<0.01$; Table 3$)$. High variation in these parameters was noted among all the experimental groups but no significant differences in lipid content or lipid : protein ratio was evident among the other experimental populations and no significant difference in protein content was evident among any of the groups. No differences were evident in lipid class distributions among any of the mesocosm crab samples (Table 4); this suggests that the reductions in lipid content and lipid:protein ratio of crabs from the medium dose basin may have reflected nutritional state, rather than a direct impact of the diesel and copper exposure. Sterol levels were nondetectable in mesocosm crab samples, a further indication of the lack of molting activity among these animals.

Species-specific responses to pollution gradients can be interpreted in relation to tissue burden data. Hydrocarbon and PCB tissue concentrations for Mytilus edulis and Carcinus maenas from Langesundfjord, as reported by Klungsøyr et al. (1988), are presented in Table 5. Tissue concentration data for mussels show a clear gradient for Sites 1 through 4 and correlate with the observed changes in lipid class distributions reported here, and histopathological and physiological responses reported elsewhere in this volume (Lowe 1988, Moore 1988, Widdows \& Johnson 1988). PCB data in crabs demonstrate a clear gradient from Sites 1 to 4 with a 3 -fold increase in tissue concentrations. Hydrocarbon data show little evidence of a predictable gradient and only slightly elevated concentrations of low molecular weight (MW) hydrocarbons were observed among crabs at Sites 3 and 4 , and high MW hydrocarbons at Site 4 . If the aromatic hydrocarbon distribution in $M$. edulis is indicative of the bioavailability of contaminants at sites in Langesundfjord, then the lack of a consistent gradient in C. maenas may indicate either metabolic turnover of aromatic hydrocarbons or differences in trophic transfer of contaminants.

Tissue concentrations of aromatic hydrocarbons in Mytilus edulis and Carcinus maenas from the mesocosm experiment are also presented in Table 5. For

Table 4. Carcinus maenas. Lipid class composition of digestive glands. Means $\pm S E, n=3$

\begin{tabular}{|c|c|c|c|c|c|c|c|c|}
\hline \multirow[t]{2}{*}{ Lipid class } & \multicolumn{4}{|c|}{ Field site } & \multicolumn{4}{|c|}{ Mesocosm basin } \\
\hline & 1 & 2 & 3 & 4 & $\mathrm{C}$ & L & $\mathrm{M}$ & $\mathrm{H}$ \\
\hline Triacylgycerol & $58.6 \pm 3.4$ & $55.7 \pm 0.8$ & $71.5 \pm 1.6^{*}$ & $65.9 \pm 1.4^{\circ}$ & $56.6 \pm 0.9$ & $59.2 \pm 1.3$ & $57.5 \pm 0.5$ & $55.4 \pm 1.5$ \\
\hline Diacylglycerol & $3.4 \pm 0.7$ & $6.3 \pm 0.1 \cdots$ & $1.5 \pm 0.9$ & $3.6 \pm 0.4$ & $3.8 \pm 0.1$ & $3.6 \pm 0.2$ & $2.8 \pm 0.9$ & $2.9 \pm 0.1$ \\
\hline Monoacylglycerol & $7.0 \pm 1.4$ & $7.9 \pm 0.2$ & $5.3 \pm 1.8$ & $6.5 \pm 0.3$ & $6.0 \pm 0.2$ & $6.3 \pm 0.3$ & $6.4 \pm 0.2$ & $7.6 \pm 1.2$ \\
\hline Free fatty acids & $7.2 \pm 1.2$ & $9.9 \pm 0.2 \cdots$ & $6.8 \pm 0.2$ & $6.8 \pm 0.3$ & $18.4 \pm 0.6$ & $16.9 \pm 0.8$ & $16.2 \pm 0.8$ & $17.7 \pm 0.8$ \\
\hline Sterols & $6.4 \pm 0.6$ & $7.4 \pm 0.2$ & $3.5 \pm 0.3 \cdots$ & $5.9 \pm 0.2$ & $0.0 \pm 0.0$ & $0.0 \pm 0.0$ & $0.0 \pm 0.0$ & $0.0 \pm 0.0$ \\
\hline Phospholipids & $17.4 \pm 0.4$ & $12.9 \pm 0.2 \cdots$ & $10.5 \pm 0.7 \cdots$ & $12.7 \pm 0.4 \cdots$ & $11.6 \pm 0.3$ & $11.9 \pm 0.2$ & $12.3 \pm 0.9$ & $12.1 \pm 0.3$ \\
\hline Other polar lipids & $0.0 \pm 0.0$ & $0.0 \pm 0.0$ & $0.0 \pm 0.0$ & $0.0 \pm 0.0$ & $3.0 \pm 0.1$ & $2.8 \pm 0.2$ & $2.9 \pm 0.1$ & $2.7 \pm 0.1$ \\
\hline Total neutral lipids & $82.6 \pm 0.4$ & $87.2 \pm 0.6^{\cdots}$ & $88.7 \pm 0.9 \cdots$ & $887 \pm 1.1 \cdots$ & $84.8 \pm 0.5$ & $86.0 \pm 0.4$ & $82.9 \pm 0.5$ & $83.6 \pm 0.6$ \\
\hline Total polar lipids & $17.4 \pm 0.4$ & $12.9 \pm 0.2 \cdots$ & $10.5 \pm 0.7 \cdots$ & $12.7 \pm 0.4^{\cdots}$ & $14.6 \pm 0.5$ & $14.7 \pm 0.6$ & $15.2 \pm 0.9$ & $14.8 \pm 0.2$ \\
\hline NL: PL ratio & $4.8 \pm 0.1$ & $6.8 \pm 0.1 \cdots$ & $8.4 \pm 0.3^{\cdots}$ & $7.0 \pm 0.3 \cdots$ & $5.8 \pm 0.1$ & $5.9 \pm 0.2$ & $5.5 \pm 0.3$ & $5.6 \pm 0.2$ \\
\hline $\begin{array}{l}\text { Triacylglycerol: } \\
\text { phospholipid ratio }\end{array}$ & $3.4 \pm 0.1$ & $4.3 \pm 0.1^{\circ}$ & $6.8 \pm 0.3^{\cdots}$ & $5.2 \pm 0.3^{*}$ & $4.9 \pm 0.1$ & $5.0 \pm 0.2$ & $4.7 \pm 0.2$ & $4.6 \pm 0.2$ \\
\hline
\end{tabular}


Table 5. Mytilus edulis and Carcinus maenas. Concentrations ( $\mu \mathrm{g} \mathrm{g}^{-1}$ dry wt) of aromatic hydrocarbons (AH) and PCBs in soft tissues of individuals from Field sites 1 to 4 and from 4 experimental basins C, L, M and H. Means \pm semi-range from 2 replicate tissue pools (10 to a pool for $M$. edulis and 4 for $C$. maenas). Low $M W$ AH: sum of naphthalene, C1-C3 naphthalenes, phenanthrene, C1-C2 phenanthrenes; medium MW AH: anthracene, dibenzothiophene, C1-C2 dibenzothiophenes; high MW $\mathrm{AH}$ : sum of fluoranthene, pyrene, benz(a)anthracene, chrysene, benz(b+k)fluoranthene, benz(e)pyrene, benz(a)pyrene, perylene (Klungsøyr et al. 1988). Because of mortality of $\mathrm{H}$ mussels these were replenished on $18 \mathrm{July}$; the concentration represents 3 wk exposure cf. $15 \mathrm{wk}$ in all other cases

\begin{tabular}{|c|c|c|c|c|c|}
\hline & Source & Low MW AH & Medium MW AH & High MW AH & PCBs \\
\hline Mytilus & Site & & & & \\
\hline \multirow[t]{9}{*}{ edulis } & 1 & $0.72 \pm 0.03$ & $0.21 \pm 0.01$ & $1.31 \pm 0.05$ & $0.077 \pm 0.006$ \\
\hline & 2 & $1.24 \pm 0.01$ & $0.45 \pm 0.01$ & $4.19 \pm 0.13$ & $0.180 \pm 0.010$ \\
\hline & 3 & $1.90 \pm 0.10$ & $0.72 \pm 0.02$ & $8.84 \pm 0.48$ & $0.225 \pm 0.015$ \\
\hline & 4 & $2.36 \pm 0.32$ & $1.26 \pm 0.25$ & $11.85 \pm 0.87$ & $0.275 \pm 0.025$ \\
\hline & \multicolumn{5}{|l|}{ Basin } \\
\hline & C & $0.65 \pm 0.06$ & $0.32 \pm 0.03$ & $0.11 \pm 0.00$ & \\
\hline & $\mathrm{L}$ & $3.57 \pm 0.12$ & $2.51 \pm 0.05$ & $0.13 \pm 0.01$ & \\
\hline & M & $13.24 \pm 0.07$ & $9.26 \pm 0.15$ & $0.25 \pm 0.03$ & \\
\hline & $\mathrm{H}$ & $7.32 \pm 0.49$ & $0.95 \pm 0.23$ & $0.05 \pm 0.01$ & \\
\hline Carcinus & Site & & & & \\
\hline \multirow[t]{9}{*}{ maenas } & 1 & $0.06 \pm 0.00$ & - & $0.020 \pm 0.004$ & $0.160 \pm 0.000$ \\
\hline & 2 & $0.07 \pm 0.00$ & $0.002 \pm 0.001$ & $0.041 \pm 0.008$ & $0.320 \pm 0.020$ \\
\hline & 3 & $0.13 \pm 0.02$ & $0.004 \pm 0.003$ & $0.041 \pm 0.003$ & $0.340 \pm 0.010$ \\
\hline & 4 & $0.12 \pm 0.03$ & $0.002 \pm 0.002$ & $0.122 \pm 0.012$ & $0.480 \pm 0.070$ \\
\hline & \multicolumn{5}{|l|}{ Basin } \\
\hline & C & $0.10 \pm 0.02$ & - & - & \\
\hline & $\mathrm{L}$ & $0.26 \pm 0.04$ & $0.017 \pm 0.003$ & $0.001 \pm 0.000$ & \\
\hline & $\mathrm{M}$ & $0.53 \pm 0.06$ & $0.033 \pm 0.010$ & $0.002 \pm 0.001$ & \\
\hline & $\mathrm{H}$ & $2.74 \pm 0.03$ & $0.124 \pm 0.010$ & $0.003 \pm 0.000$ & \\
\hline
\end{tabular}

mussels from $\mathrm{C}, \mathrm{L}$ and $\mathrm{M}$ basins, a clear gradient of increases in low and medium MW hydrocarbons is evident; only a 2-fold increase in high MW hydrocarbons was observed between control and medium dose basins. Because of high mortality after 7 wk exposure in the high dose basin, mussels had to be replaced and those sampled for hydrocarbon analyses were only exposed for $18 \mathrm{~d}$. Thus, total aromatic hydrocarbon concentrations in mussels from the high dose basin were less than those measured from the medium dose basin, although the actual concentrations at the time of sampling for biological analyses are projected to be higher (Widdows \& Johnson 1988). Aromatic hydrocarbon concentrations in $C$. maenas demonstrate a clear gradient in low MW hydrocarbons in the mesocosm basins but only trace amounts of medium and high MW aromatic hydrocarbons were evident.

\section{DISCUSSION}

Physiological effects of exposure to lipophilic organic contaminants are modified by contaminant bioavailability, the ability of the organism to accumulate and metabolise various contaminants, the fate of metabol- ised products, and the interference of contaminants with normal metabolic processes. Differences in interspecific sensitivity and seasonal variation in intraspecific response may be related to dependency on specific metabolic processes, such as storage and mobilization of lipid reserves during reproductive events, and synthesis and activation of steroid hormones during molting (review by Capuzzo 1987). Comparison of the responses of Mytilus edulis and Carcinus maenas in field and mesocosm experiments demonstrate such interspecific and intraspecific variations in response.

Mytilus edulis collected along the contaminant gradient in Langesundfjord had increased levels of triacylglycerol and higher triacylglycerol:phospholipid ratios, suggesting decreased mobilisation of triacylglycerols into phospholipid pools with potential consequences on membrane structure and function. This response is consistent with the observations of Lowe (1988) and Moore (1988) of histological and histochemical evidence of lipid and lipofuscin accumulation, increased cell vacuolation in the digestive gland, and tubule degeneration in the digestive gland, the latter being evident at Site 3. Lysosomal dysfunction and membrane disruption may be related to lipid peroxida- 
tion and cytosolic protein catabolism (Moore \& Viarengo 1987, Moore et al. 1987) and would support the suggestion by Stegeman (1985) that metabolism of xenobiotics in marine molluscs might include peroxidative mechanisms

Mytilus edulis from the mesocosm experiment did not show consistent trends among the various exposure conditions, in part reflecting differences in reproductive condition of the various experimental groups. For mussels from the medium and low dose basins, reductions in triacylglycerol: phospholipid ratios and neutral lipid:polar lipid ratios reflect the nutritional status of these animals in combination with exposure conditions This is consistent with the histological and histopathological observations of Lowe (1988) and Moore (1988) and the physiological observations of Widdows \& Johnson (1988). Mussels from the high dose basin were distinctly different from the other experimental groups and had a significant decrease in phospholipid content, suggesting membrane destruction, and marked increases in both the neutral lipid:polar lipid ratios and the triacylglycerol: phospholipid ratios. This group of mussels also demonstrated a high degree of lysosomal disturbance and cellular degeneration (Moore 1988) and was the only group among the mussels from the mesocosm experiment to demonstrate signs of gamete degeneration and digestive tubule degeneration (Lowe 1988). Thus, the observed changes in lipid class distributions of $M$. edulis from both field and mesocosm studies are consistent with observations of histological and histopathological changes and correlate well with body burden data for tissue concentrations of aromatic hydrocarbons and polychlorinated biphenyls. The combined effects of multiple contaminants on responses of $M$. edulis has been discussed by Widdows \& Johnson (1988).

For populations of Carcinus maenas collected along the contaminant gradient in Langesundfjord, elevations in triacylglycerol content, reductions in phospholipid and sterol content, and increases in the neutral lipid:polar lipid ratios and triacylglycerol:phospholipid ratios were observed. These responses suggest that alterations in the mobilisation of triacylglycerols, sterol turnover and tissue degeneration may be taking place. Responses to the contaminant gradient are consistent with observations of changes in respiration rate of C. maenas reported by Bayne \& Thurberg (1988) and elevations in glutathione transferase activity for C. maenas reported by Lee (1988); populations at Site 3 appeared to be the most impacted. The responses are not consistent with body burden data of aromatic hydrocarbons nor with the trends observed in PCB concentrations that indicate the highest concentration of PCBs at Site 4. The only distinction in aromatic hydrocarbon distribution between crabs from Site 3 and those from Site 4 is a slight elevation in naphthalene and its substituted derivatives at Site 3 (Klungsøyr et al. 1988). Biotransformation of lipophilic contaminants through cytochrome P-450 mediated mixed function oxidases have been identified in marine decapod crustaceans (Lee 1981) although considerable seasonal variation has been noted (Lee 1982). Mixed function oxidases are also involved in the activation of ecdysone during the molt cycle of crustaceans and seasonal variations in detoxification may be linked to the molt cycle.

Crabs from the mesocosm experiment show no evidence of alterations in lipid class distribution in spite of a consistent trend in aromatic hydrocarbon tissue concentrations in line with the treatments. This is consistent with other studies of Carcinus maenas in the mesocosm basins as no difference in either respiration rate or glutathione transferase activity were observed (Bayne \& Thurberg 1988, Lee 1988). In comparison with field populations of $C$. maenas, there is no evidence of metabolic turnover of aromatic hydrocarbons or evidence of molting among any of the crab populations from the mesocosm experiment, possibly as a result of the lower temperature in the mesocosm basins.

Although Anderson (1977) observed changes in respiratory activity of crustaceans in response to watersoluble fractions of petroleum hydrocarbons, he concluded that there was little agreement between sublethal responses and tissue hydrocarbon burdens. Anderson et al. (1980) further demonstrated that the accumulation of di- and tri-aromatic hydrocarbons in tissues of decapod crustaceans could not be used to explain toxic effects. A clearer relationship between toxic effects and accumulated metabolites has been suggested (Sanborn \& Malins 1977, 1980, Capuzzo et al. 1984, Capuzzo 1987). If changes in respiratory activity of Carcinus maenas are linked with detoxification and molting activity, then the lack of response in the mesocosm experiment would not be unexpected. If tissue hydrocarbon data for Mytilus edulis from Langesundfjord are representative of the bioavailability of contaminants along the contaminant gradient, one can assume that $C$. maenas populations are exposed to a similar gradient and differential responses are the result of metabolic capacity for detoxification and possible differences in trophic transfer.

In conclusion, lipid class distributions of Mytilus edulis and Carcinus maenas are responsive to contaminant gradients of lipophilic organic contaminants and provide biochemical evidence of structural and functional alterations in the digestive gland. Such responses are sensitive to the molecular processes involved in uptake, retention and loss of lipophilic contaminants and metabolic capacity for detoxification may be linked to toxic responses. 


\section{LITERATURE CITED}

Anderson, J. W. (1977). Responses to sublethal levels of petroleum hydrocarbons: Are they sensitive indicators and do they correlate with tissue contamination? In: Wolfe, D. A. (ed.) Fate and effects of petroleum hydrocarbons in marine ecosystems and organisms. Pergamon Press, New York, p. 95-114

Anderson, J. W., Kiesser, S. L., Blaylock, J. W (1980). The cumulative effect of petroleum hydrocarbons on marine crustaceans during constant exposure. Rapp. P.-v. Réun. Cons. int. Explor Mer 179: 62-70

Bakke, T., Follum, O. A., Moe, K. A., Sorensen, K. (1988). The GEEP Workshop: a mesocosm exposures. Mar Ecol. Prog. Ser. 46: 13-18

Bayne, B. L., Thurberg, F. P. (1988). Physiological measurements on Nucula tenuis and on isolated gills of Mytilus edulis and Carcinus maenas. Mar. Ecol. Prog. Ser. 46: 129-134

Caldwell, R. S., Rosene, B. A., Calderone, E. M. (1979). Fatty acid composition of phospholipids in thermally acclimating sculpins Leptocottus armatus treated with polychlorinated biphenyls Aroclor 1254. In: Vernberg, W. B., Thurberg, F. P., Calabrese, A., Vernberg, F. J. (eds.) Marine pollution: functional responses. Academic Press, New York, p. $271-290$

Capuzzo, J. M., Lancaster, B. A., Sasaki, G. C. (1984). The effects of petroleum hydrocarbons on lipid metabolism and energetics of larval development and metamorphosis in the American lobster Homarus americanus Milne Edwards). Mar. environ. Res. 14: 201-228

Capuzzo, J. M. (1987). Biological effects of petroleum hydrocarbons: assessments from experimental results. In: Boesch, D. F., Rabalais, N. N. (eds.) Long-term environmental effects of offshore oil and gas development Elsevier Applied Science, London, p. 343-410

Christie, W. W., Hunter, M. L. (1979). Separation of neutral lipids on chromarods. J. Chromatogr. 171:517-518

Darsie, J., Gosha, J. K., Holman, R. T (1976). Induction of abnormal fatty acid metabolism and essential fatty acid deficiency in rats by dietary DDT Arch. Biochem. Biophys. 175: $262-269$

Dzogbefia, V P., Kling, D., Gamble, W. (1978). Polychlorinated biphenyls in vivo and in vitro modifications of phospholipid and glyceride biosynthesis. J. environ. Pathol. Toxicol. 1.841-856

Follum, O. A., Moe, K. A. (1988). The GEEP Workshop: field sampling. Mar. Ecol. Prog. Ser. 46: 7-12

Innis, S. M., Clandinin, M. T. (1981). Separation of phospholipids on chromarods. J. Chromatogr. 205: 490-492

Kato, N., Kawai, K., Yoshida, A. (1982). Effects of dietary polychlorinated biphenyls and protein level on liver and serum lipid metabolism of rats. Agric. Biol. Chem. 46: $703-708$

Klungsøyr, J., Wilhelmsen, S., Westrheim, K., Saetvedt, E.,
Palmork, K. H. (1988). The GEEP Workshop: organic chemical analyses. Mar. Ecol. Prog. Ser. 46: 19-26

Lee, R. F. (1981). Mixed function oxygenases (MFO) in marine invertebrates. Mar Biol. Lett. 2: 87-105

Lee, R. F. (1982). Cytochrome P-450 dependent mixed function oxygenase systems in marsh crabs. In: Vernberg W. B., Calabrese, A., Thurberg, F. P., Vernberg, F. J. (eds.) Physiological mechanisms of marine pollutant toxicity. Academic Press, New York, p. 145-159

Lee, R. F. (1988). Glutathione S-transferase in marine invertebrates from Langesundfjord. Mar Ecol. Prog. Ser 46: 33-36

Lowe, D. M. (1988). Alterations in cellular structure of Mytilus edulis resulting from exposure to environmental contaminants under field and experimental conditions. Mar Ecol. Prog. Ser. 46: 91-100

Moore, M. N. (1988). Cytochemical responses of the lysosomal system and NADPH-ferrihemoprotein reductase in molluscan digestive cells to environmental and experimental exposure to xenobiotics. Mar. Ecol. Prog. Ser. 46: 81-89

Moore, M. N., Livingstone, D. R., Widdows, J. (1988). Hydrocarbons in marine molluscs: Biological effects and ecological consequences. In: Varanasi, U. (ed.) Aromatic hydrocarbon metabolism by aquatic organisms. CRC Press, Inc. (in press)

Moore, M. N., Viarengo, A. (1987). Lysosomal membrane fragility and catabolism of cytosolic proteins: Evidence for a direct relationship. Experientia 43: 320-323

Raymont, J. E. G., Austin, J., Linford, E. (1964). Biochemical studies on marine zooplankton. I. The biochemical composition of Neomysis integer. J. Cons. perm. int. Explor Mer 28: 354-363

Reich, T., Depew, M. C., Marks, G. S., Singer, M. A., Wan, J. K. S. (1981). Effect of polychlorinated biphenyls on phospholipid membrane fluidity. J. environ. Sci. Health, Part A, Environ. Sci. Eng. 16: 65-72

Sanborn, H. R., Malins, D. C. (1977). Toxicity and metabolism of naphthalene: A study with marine larval invertebrates. Proc. Soc. exp. Biol. Med. 154: 151-155

Sanborn, H. R., Malins, D. C. (1980). The disposition of aromatic hydrocarbons in adult spot shrimp Pandalus platyceros and the formation of metabolites of naphthalene in adult and larval spot shrimp. Xenobiotica 10: 193-200

Sasaki, G. C., Capuzzo, J. M. (1984). Degradation of Artemia lipids under storage. Comp. Biochem. Physiol. 78B $525-531$

Sokal, R. R., Rohlf, F. J. (1981). Biometry. W. H. Freeman \& Co., San Francisco

Stegeman, J. J. (1985). Benzo[a]pyrene oxidation and microsomal enzyme activity in the mussel (Mytilus edulis) and other bivalve mollusc species from the Western $\mathrm{N}$. Atlantic. Mar. Biol. 89: 21-30

Widdows, J., Johnson, D. (1988). Physiological energetics of Mytilus edulis: Scope for Growth. Mar. Ecol. Prog. Ser. 46: $113-121$ 